\title{
Recurrent oculomotor palsy due to haemorrhage in pituitary adenoma
}

\author{
S. MOHANTY \\ M.S., M.Ch.(Neuro) \\ Section of Neurosurgery, Department of Surgery, Institute of Medical Sciences, \\ Banaras Hindu University, Varanasi-221005 India
}

\begin{abstract}
Summary
Haemorrhage in pituitary adenoma is an unusual cause of recurrent oculomotor palsy. Three episodes of right oculomotor palsy are reported from a patient having haemorrhage in pituitary adenoma. Early operation and decompression of haemorrhagic pituitary adenoma should be performed so that vision may be preserved and recovery of oculomotor palsy be assured.
\end{abstract}

\section{Introduction}

Oculomotor palsy due to adenoma of the pituitary gland is uncommon (Bardram, 1949). Walsh (1957) reported an incidence of 8 to $11 \%$ in various series. However, only one case with recurrent attacks of oculomotor palsy in pituitary adenoma has been reported (Weinberger, Adler and Grant, 1940). In the present report 3 episodes are described of oculomotor palsy in a patient having pituitary adenoma with evidence of haemorrhage.

\section{Case report}

A 49-year-old male was admitted to hospital with progressive dimunition of vision, diplopia and headache of 15 days' duration and ptosis of the right eye for the last 4 days. He had had an episode of severe headache and vomiting 2 years before. At that time he had diplopia and partial ptosis of the right eye which fully recovered within 4 days; he had a second episode of ptosis of the right eye associated with headache 8 months later from which he recovered in 2 months. There was no history of loss of consciousness nor of endocrine symptoms.

General physical examination was non-contributory. His higher mental functions were normal. The first cranial nerve was normal. He could count fingers with the left eye at $0.61 \mathrm{~m}$, and only perception of light was present in the right eye. Confrontation test revealed a field defect in the left temporal and left inner lower quadrant; in the right eye, light was perceived only in a portion of the nasal field. Fundus examination revealed primary optic atrophy in both eyes. There was complete 3rd nerve palsy on the right side with full ptosis and fixed dilated pupil. Other cranial nerves were normal, and other neurological examinations revealed no further abnormalities. Routine urine examination and haemogram were normal. Fasting blood sugar was $5.7 \mathrm{mmol} / \mathrm{l}$ and blood urea was $3.32 \mathrm{mmol} / \mathrm{l}$. A lateral skull X-ray revealed a markedly enlarged sella with undermining of the anterior clinoid process (Fig. 1). A right carotid angiogram excluded an internal carotid aneurysm of A-V malformation and revealed supra- and para-sellar extension of the sellar mass.

The patient was given intramuscular dexamethasone $4 \mathrm{mg} / 6 \mathrm{hr}$ for 5 days. This improved his feeling of wellbeing but there was no change in vision. A right frontal craniotomy was performed 8 days after admission. The optic nerves were raised by the? supra-sellar mass and were flattened. Aspiration of the sellar mass removed $7 \mathrm{ml}$ of thick, dark brown fluid. The capsule was incised, and soft, friable tumour from within the sella was curetted and aspirated. Biopsy revealed a chromophobe adenoma with extensive necrosis. The patient made an uneventful recovery. Vision in both eyes improved by the 2nd postoperative day but there was no change in the ptosis in the first week after operation (Fig. 2). The patient was given radiotherapy, and one month after operation, both the ptosis and the right 3rd nerve palsy recovered (Fig. 3).

\section{Discussion}

Haemorrhage occurs in pituitary adenoma in $25 \%$ of cases (Mohanty et al., 1977). A high incidence of haemorrhage is relative to the large size of the tumour. Such haemorrhage may clinically manifest as pituitary apoplexy (Brougham, Heusner and Adams, 1950), recurrent subarachnoid haemorrhage (Mohanty et al., 1979), rapid or sudden loss of vision and ocular palsy (Benjamin, 1929; Walsh, 1957). The 3rd nerve is often implicated in large pituitary adenomas (Walsh, 1957). Third nerve paralysis which recurs as a manifestation of migraine is often presumed to be vascular (Bramwell, 1933) or consequent on cerebral oedema (Harrington and Flocks, 1953).

It is improbable that an enlarging adenoma of the 


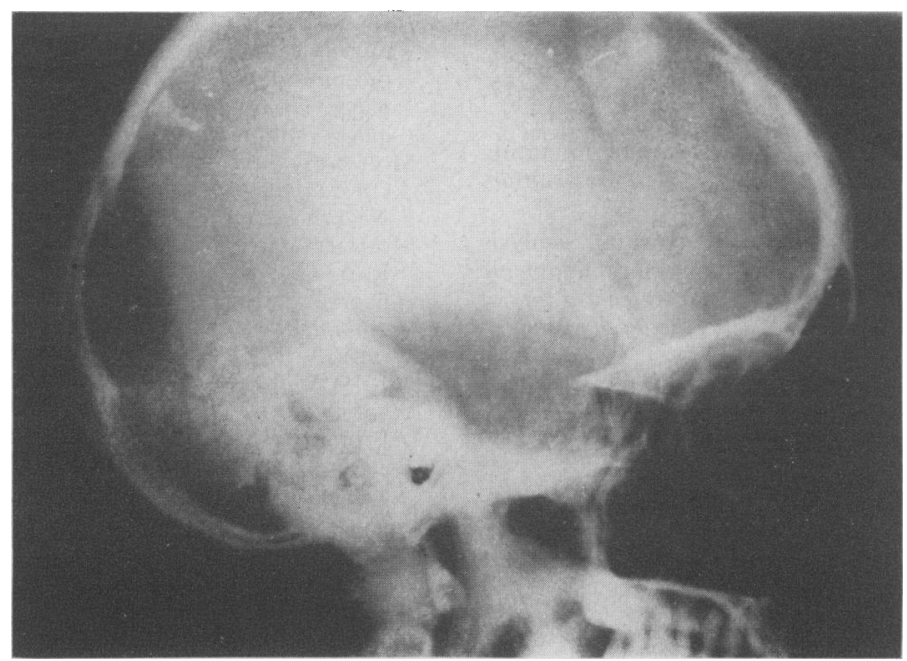

FIG. 1. Lateral skull X-ray showing markedly enlarged sella.

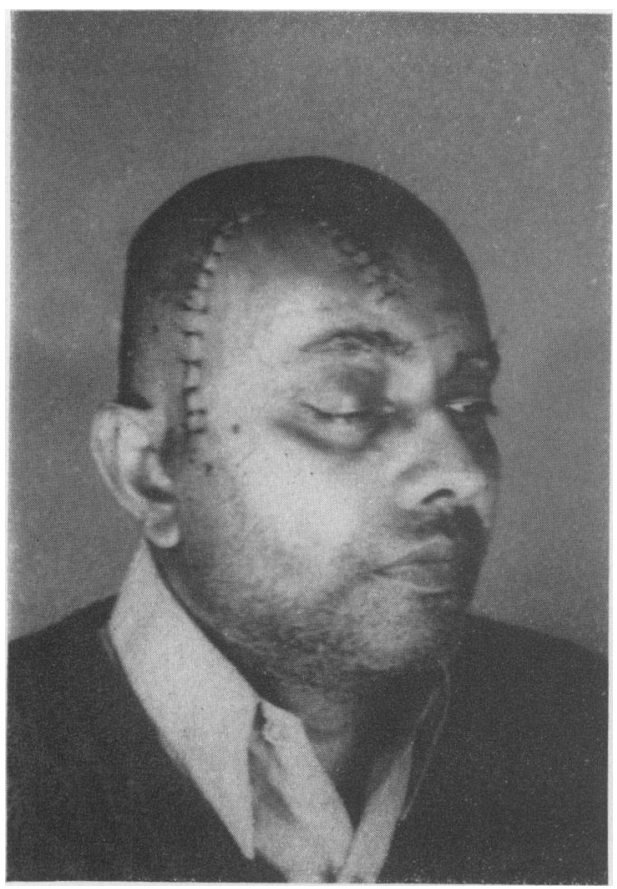

FIG. 2. Photograph of the patient 7 days after craniotomy and decompression of pituitary adenoma. There is ptosis of the right eye.

pituitary could cause a 3rd-nerve palsy which recovers spontaneously. However, the present case shows that repeated small haemorrhages may produce reversible compression of the 3 rd nerve and

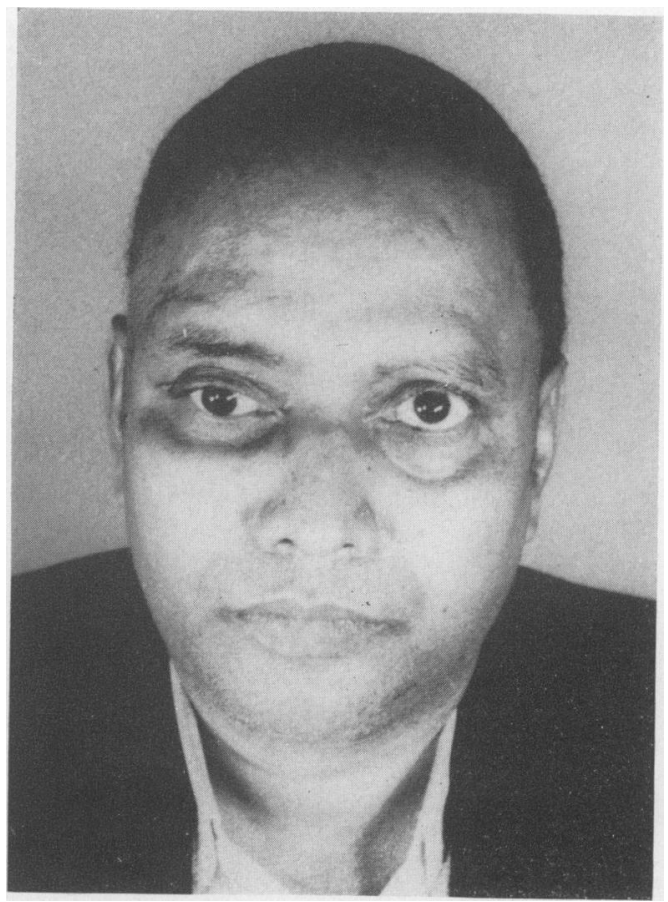

FIG. 3. The same patient one month after operation and irradiation. Ptosis has resolved.

that a massive haemorrhage, causing pressure within the cavernous sinus, may lead to permanent oculomotor palsy (Weinberger et al., 1940) unless it is surgically decompressed. 


\section{References}

BARDRAM, M.T. (1949) Oculomotor pareses and non-paretic diplopia in pituitary adenomata. Acta ophthalmologica, 27, 225.

Benjamin, J.E. (1929) Pituitary tumor with fulminating symptoms. Journal of the American Medical Association, 92, 1755.

Bramwell, E. (1933) Etiology of recurrent ocular paralysis including periodic ocular paralysis and ophthalmoplegic migraine. Transactions of the Medico-Chirurgical Society of Edinburgh, pp. 209, 1932/33: In: Edinburgh Medical Journal.

Brougham, M., Heusner, A.P. \& Adams, R.D. (1950) Acute degenerative changes in adenomas of the pituitary body with special reference to pituitary apoplexy. Journal of Neurosurgery, 7, 421.
Harrington, D.O. \& Flocks, M. (1953) Ophthalmoplegic migraine. A discussion of its pathogenesis with a report of the pathologic findings in a case of recurrent oculomotor palsy. Transactions of the American Academy of Ophthalmology and Otolaryngology, 57, 517.

Mohanty, S., Tandon, P.N., Banerji, A.K. \& Prakash, B. (1977) Haemorrhage in pituitary adenomas. Journal of Neurology, Neurosurgery and Psychiatry, 40, 987.

Mohanty, S., Thacker, A.K., Katiyar, B.C., Misra, S., RAO, C.J. \& RAO, S.N. (1979) Recurrent subarachnoid haemorrhage in pituitary adenoma. Journal of the Association of Physicians of India, 27 (6), 539.

WaLSH, F.B. (1957) Clinico Neuro-Ophthalmology, pp. $1013-$ 1019, William \& Wilkins Company, Baltimore.

Weinberger, L.M., Adler, F.H. \& Grant, F.C. (1940) Primary pituitary adenoma and the syndrome of the cavernous sinus. Archives of Ophthalmology, 24, 1197. 